\title{
El elemento estético indígena y/o prehispánico en el patrimonio artístico salvadoreño como expre- sión de la identidad nacional ${ }^{1}$
}

José Heriberto Erquicia Cruz.

Durante el período colonial hispanoamericano, muchos elementos estéticos prehispánicos, tales como símbolos, distintivos, emblemas, imágenes e iconos, eran parte de esa gama de componentes que se visualizaban en la arquitectura, la escultura, la pintura y en general en muchas de las expresiones artísticas, que como tal eran parte de la admiración que se tenía de lo antiguo, pero también eran parte de la expresión de aquellos indígenas que depositaban y plasmaban su etnicidad en dichas obras. Mientras que para el siglo $\mathrm{XX}$, cuando se estaba edificando el Estado salvadoreño moderno, el elemento estético indígena y/o prehispánico en las expresiones artísticas jugó un papel diferente del que se manifestaba en el antiguo régimen colonial.

Ese papel que jugaría más tarde lo indígena, ya sea este arqueológico o folclórico y que posteriormente se volvería en lo campesino - costumbrista o mágico - y muchas veces en lo rural - pobre, desprotegido y excluido-, ha pasado por una serie de etapas hasta nuestros día. Por supuesto, es reflejo del contexto histórico-social que ha ido desarrollándose a través del tiempo en la sociedad; entorno que se expresa claramente en el patrimonio artístico salvadoreño, como claro referente de su identidad nacional.

En la actualidad entendemos como objeto artístico, el que un consenso general reconoce como tal, independientemente de sus cualidades, como son formas, proporciones, colores y otras. (Manrique, 1997: 59).

1 Artículo elaborado a solicitud del Museo de Arte de El Salvador MARTE, preparado para acompañar la exposición denominada "Por los signos de los siglos. Aproximación al arte prehispánico". El autor agradece la colaboración brindada por Leonardo Regalado para la elaboración del presente artículo. 


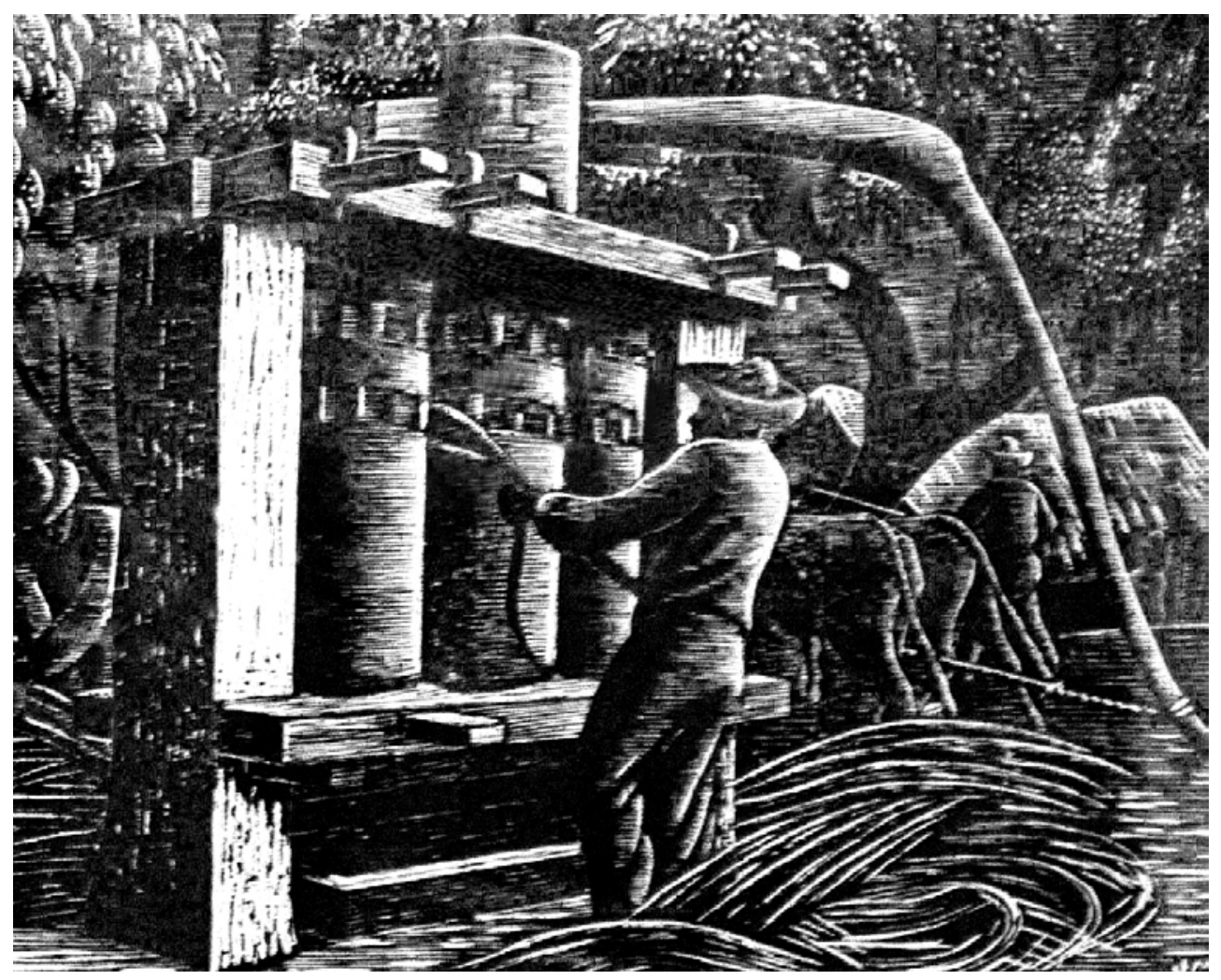

José Mejía Vides, Trapiche; xilografía. 32 x 39 cm.

Hacia la segunda mitad siglo XIX, se crea la categoría de patrimonio cultural, más como patrimonio histórico-artístico, con el fin de dar cuerpo a los recién creados Estados-Nacionales (Bermejo Barrera, 1986), en el entendido que ese patrimonio artístico-cultural nos brindaría "nuestra personalidad como humanos, como miembros de una nación, como parte de una comunidad" (Manrique, 1997:61).

Así se edifica una relación intrínseca entre la comunidad y las instituciones que el Estado crearía o reforzaría para cohesionar a los nuevos ciudadanos de la "nación moderna", dichas instituciones fueron la escuela - educación pública o nacional - , el museo, el mapa, el censo y el periódico — revistas, semanarios, y demás - (Anderson, 2007). Esa nación es, desde una visión antropológica como: una comunidad política imaginada construida culturalmente como una entidad soberana dentro de determinados límites espaciales... (Ibíd. 23). 
De esta manera, las instituciones del Estado jugarían un papel clave en la formación de la identidad nacional salvadoreña, identidad que se construiría a partir de un nuevo modelo de ciudadano civilizado, moderno, mestizo, étnico y culturalmente homogéneo. Sin embargo, esta construcción de la nacionalidad salvadoreña no dejó de llenarse de contradicciones, ya que, al mismo tiempo, invisibilizó y negó las identidades indígenas, concebidas como símbolo del atraso y del conservadurismo.

Por su parte, Hobsbawm contribuye al alcance de cómo esta comunidad política imaginada llega a convertirse en un valor de la población que antepone los intereses nacionales por sobre cualquier otro (Hobsbawm, 2002: 3-15). Es así que la religión cívica, inculcada entre la población por medio de diversos instrumentos, tales como la educación primaria, el ceremonial cívico, la estatuaria heroica y el culto a los símbolos patrios, es un fenómeno estrechamente vinculado con la invención de tradiciones, las cuales son fomentadas por el Estado para inculcar en los ciudadanos una idea de lealtad y obligación hacia el mismo (López Bernal, 2007: 20).

Los ideólogos de Estado, elites intelectuales, políticas y económicas, se inscribieron en un proceso que justificó y legitimó su existencia, no sin falsear la invención de tradiciones (Hobsbawm, 2002), y personajes míticos de ascendencia indígena, de la idea de un pasado glorioso, el cual se esfumó, pero que estaban decididos a construir de nuevo desde los ideales del liberalismo.

Es así que El Salvador - del último cuarto del siglo XIX y las tres primeras décadas del siglo XX - no quedó exento de las contribuciones desde la academia, las elites y los intelectuales, con la creación del Museo Nacional del Salvador en 1883, el cual tenía como uno de su objetivos fomentar los intereses económicos e intelectuales de la República, siendo además reclamado por el estado de cultura del pueblo... (D. O. 1883: Nº. 239), además que expondría una sección de antigüedades, historia y bellas artes.

Tal como ocurrió en el resto de Hispanoamérica, el Estado debía fundamentarse sobre la base de una cultura también nacional, que incorporara la cultura indígena; así se comienza a construir la historia patria - oficial - impartida en los establecimientos educativos, historia que formaba parte de la educación cívico-política de los ciudadanos, destinada a crear conciencia histórica nacionalista que requería el Estado en construcción (Lombardo, 1997: 199-200). Como afirma Lombardo, es en este sentido que el gobierno nacional, repre- 
sentado por una clase minoritaria emergente, debía reivindicarse con el indio; y al rescatar la cultura de sus antepasados hacía también suya la tradición de la clase subalterna de mayoría en el país, con lo que afirmaba su propia legitimidad política ante las mayorías (Ibíd. 200). En este contexto, el monumento era expresión de la cultura del pueblo, y el estudio de esos testimonios les permitía develar la génesis, de la historia de los primeros pobladores de dichos territorios (Florescano, 1997: 151).

De tal manera que, de acuerdo con la perspectiva etno-nacionalista o histórico-culturalista, las naciones siempre requieren de elementos étnicos. No es concebible una nación que no tenga mitos y recuerdos colectivos de un hogar territorial. Para Smith, uno de los factores claves en la formación de una nación es que debe tener antecedentes étnicos de importancia [...] vagos o inventados, que construyan [...] una mitología y un simbolismo coherentes [...] como condición para la supervivencia y la unidad nacional (Smith, 1997: 27-28).

Como parte del proyecto liberal decimonónico, aparece el mestizaje como discurso del nacionalismo salvadoreño, pero no solamente como discurso, sino que va de la mano de prácticas de exterminio e invisibilización de las comunidades indígenas. El mestizaje plantea una ideología de homogenización étnica o de mezcla racial; excluye a los que se consideran no mezclados y adopta el "blanqueamiento cultural", como la manera de volverse más urbano, cristiano, civilizado, menos rural, indígena o negro (Wade, 2000: 101).

En el caso salvadoreño, a inicios del siglo XX, los indígenas fueron reintegrados a la nación mediante elementos simbólicos, como grupos autóctonos, como los habitantes prístinos del territorio salvadoreño, poseedores de ciertos secretos de la identidad nacional (Alvarenga, 2004: 363). A mediados de la década de 1910, los intelectuales redefinieron el discurso nacional, enfatizándolo más en la cuestión cultura. Es ahí en donde el indio salvadoreño se vuelve importante dentro del discurso nacionalista, como lo más puro del alma nacional (López Bernal, 2007a: 191). Sin embargo, el indio que se reivindica como sujeto relevante dentro de ese proceso de construcción de la nación, es el indio ancestral, el que surge a través de la arqueología, no el que habitaba en las comunidades indígenas de El Salvador.

El mestizaje, como parte fundamental de la ideología nacionalista, permitió a los intelectuales de la década de 1920 desempeñar un papel importante en 
la formación de la nación, inventando y creando símbolos antiimperialistas; además de imágenes simbólicas de la nación mestiza que permitió la inclusión de grupos subalternos (campesinos, proletarios y pequeños comerciantes) (Gould, 2004: 396-397).

La versión salvadoreña del mestizaje, al igual que la mexicana y la nicaragüense, valoraba mucho la contribución indígena a la idea de identidad nacional; surge en la década de 1920 una intelligentsia nacionalista, que pretendía encontrar una identidad salvadoreña en los orígenes indígenas de Cuscatlán (Gould, 2004: 398). Como parte esencial del movimiento nacionalista, se incorporó el folclor indígena y el estudio del nahuat (Ibíd.).

Siempre en la década de 1920, con la reivindicación del mito de Atlacatl, - héroe indígena que supuestamente habría luchado en contra de los conquistadores españoles del siglo XVI-, dicho personaje no fue más que un inventó de algunos de los intelectuales de finales del siglo XIX y que reprodujeron otros y con mayor fuerza a principios del XX, el cual se utilizó para llamar a la unidad y cohesión de la nación a partir de un héroe mítico, valiente y rebelde.

Según Soto y Díaz, fue luego de 1920, que el Estado, junto a la prensa y los intelectuales, cuando se produjo el mayor intento oficial salvadoreño de apropiarse del pasado prehispánico y representar entre los símbolos de la nación al indígena (Soto Quirós y Díaz Arias, 2007:105).

Como señala López Bernal, durante el decenio de 1920 los esfuerzos por construir una identidad nacional fueron importantes, con la reelaboración de la imagen de Atlacatl; este fue motivo de inspiración para diferentes manifestaciones artísticas (López Bernal, 2007: 163).

Uno de los ejemplos más relevantes es la obra del escultor Valentín Estrada, quien trata de plastificar en bronce la figura del "Cacique Atlacatl", estatua que llegó a El Salvador en 1928 desde España, y que según Estrada: "la idea de hacer la escultura del indio Atlacatl [...] Era la expresión de un indio americano, que desea volver a su patria y a su tierra; y es así que lo pongo en actitud de vigilia" (López Bernal: 2007: 164). Podemos mencionar también el medallón de bronce elaborado por Joaquín Aguilar Guzmán, que representa una efigie de Atlacatl, y que se colocó en el tímpano del portón oriental (fachada principal) del edificio del Palacio Nacional (Ibíd.). 
Para ese momento era tan fuerte el culto a Atlacatl y el creciente indigenismo que, en 1927, Jean Genet anunciaba una noticia en Le Temps de 1925 en París, suscrita por Louis Guilaine, en la que El Salvador quería cambiar su nombre por el de República de Cuscatlán y San Salvador por el de Atlacatl (Escalante Arce, 1989: 209).

Finalizaba el decenio de 1920, a escala mundial afectaba la gran depresión económica de 1929 y otros factores políticos que influirían a escala regional. En El Salvador había sido una época interesante en la consolidación de la "identidad nacional". Dicha década parece haber sido clave en apostarle a la investigación arqueológica y la creación del "mito de origen”. Mucho tendrán que ver las corrientes posrevolucionarias que llegan de México después de 1910; estas quieren reivindicar un pasado prehispánico glorioso, en el que la arqueología juega un papel legitimador a través de los discursos. Con nuevos hallazgos se va configurando la idea de una identidad prístina que, aunque con relaciones de parentesco con las demás naciones vecinas, tratan de verla como una identidad cultural única, autóctona, salvadoreña. Es desde ahí de donde la estética, ya sea esta prehispánica o indígena, vería una marcada influencia en las artes en general.

Vendría la década de 1930, y se publicaría en 1931 el último censo nacional de población de la historia de El Salvador, en donde se incluiría la categoría de raza (etnia); en el que se contabilizaban los ciudadanos que pertenecían a los diferentes grupos étnicos que habitaban en el territorio; de alguna manera asumiendo que existían otras identidades étnicas. El departamento de Historia realizaría sus últimas expediciones arqueológicas y la última publicación de su revista, hasta que se reanudó en 1940; asimismo la situación políticaeconómica y social de El Salvador era difícil. La caída de los precios internacionales del café, aunado a la incapacidad mostrada por el gobierno de Arturo Araujo para resolver las demandas de la población, generó un golpe de Estado, que seguiría de una insurrección en el occidente de El Salvador, que muchos llamarían un conflicto étnico indígena-ladino (Ching, López Bernal y Tilley, 2007; Gould, Lauria-Santiago; 2008, Lara-Martínez, 2009; Lindo, Ching y Lara-Martínez, 2010); y la posterior reacción por parte del ejército salvadoreño en los hechos de enero y febrero de 1932, culminando con una era que obligó a redefinir el discurso nacionalista y del Estado-Nación que se venía conformando. Estos hechos, en definitiva, marcaron el "parteaguas" en la historia moderna de El Salvador. 
Luego de estos hechos, surge en El Salvador el indigenismo de negación, como lo denomina Alejandro Dagoberto Marroquín (Marroquín, 1975: 767), constituyéndose en aquella política cultural-indigenista que implanta el régimen de Martínez a mediados de la década de 1930, en la que se quería presentar ante el mundo a un Estado salvadoreño preocupado por la causa indigenista; una política de exportación (Ibíd.). Es así, que desde 1935, el gobierno efectuó una política de promoción de las artes y del turismo en lugar de un indigenismo pleno, sustituyó la antropología por la pintura y el turismo, convirtió cualquier acción indigenista en folclórica y típica (Lara-Martínez, 2005: 100-120).

La estética indígena y/o prehispánica entra a representarse en las expresiones artísticas salvadoreñas, luego del fortalecimiento de la nación y de la fijación de la identidad nacional salvadoreña, y con mayor fuerza a partir de la década de 1920.

Así, tenemos la obra de Miguel Ortiz Villacorta (1887-1963), que con sus conocimientos adquiridos en México logra plasmar, del paisaje rural nacional, la importancia del indígena prehispánico y actual (MARTE, 2007:24). De valor es la creación de la obra de María de Baratta, para la folclorización de lo indígena entre las décadas de 1920 y 1940; así como el aporte de Augusto Baratta con la investigación de la arquitectura prehispánica llevada a cabo en Cihuatán a finales del decenio de 1920, y de la que propondría una arquitectura moderna con elementos estéticos prehispánicos, de las cuales algunas edificaciones se pueden observar en la actualidad en San Salvador.

Salarrué, como profesor de mitología y arte decorativo indígena de la Escuela de Bellas Artes, desde 1929 (MARTE, 2007: 29), no escapa a incluir en todas las formas de expresión artística que produce los elementos tanto prehispánicos como los de la población indígena que vivía en El Salvador de su época.

De gran significancia resultan las obras de Valentín Estrada, por sus motivos netamente prehispánicos, utilizando dicha estética en monumentos públicos, como la escultura de Atlacatl de 1927, y en la década de 1950 en parques nacionales, con las figuras Chaac Mol, en el parque nacional Balboa de Los Planes de Renderos, San Salvador, y otra figura de Atonal en el balneario nacional de Atecozol, en Izalco, Sonsonate. Con ello, el Estado pretendía llevar lo indígena a través de la estética a un plano monumental para lograr efectos de legitimidad de la identidad nacional. El artista Pedro Ángel Espinoza, luego 


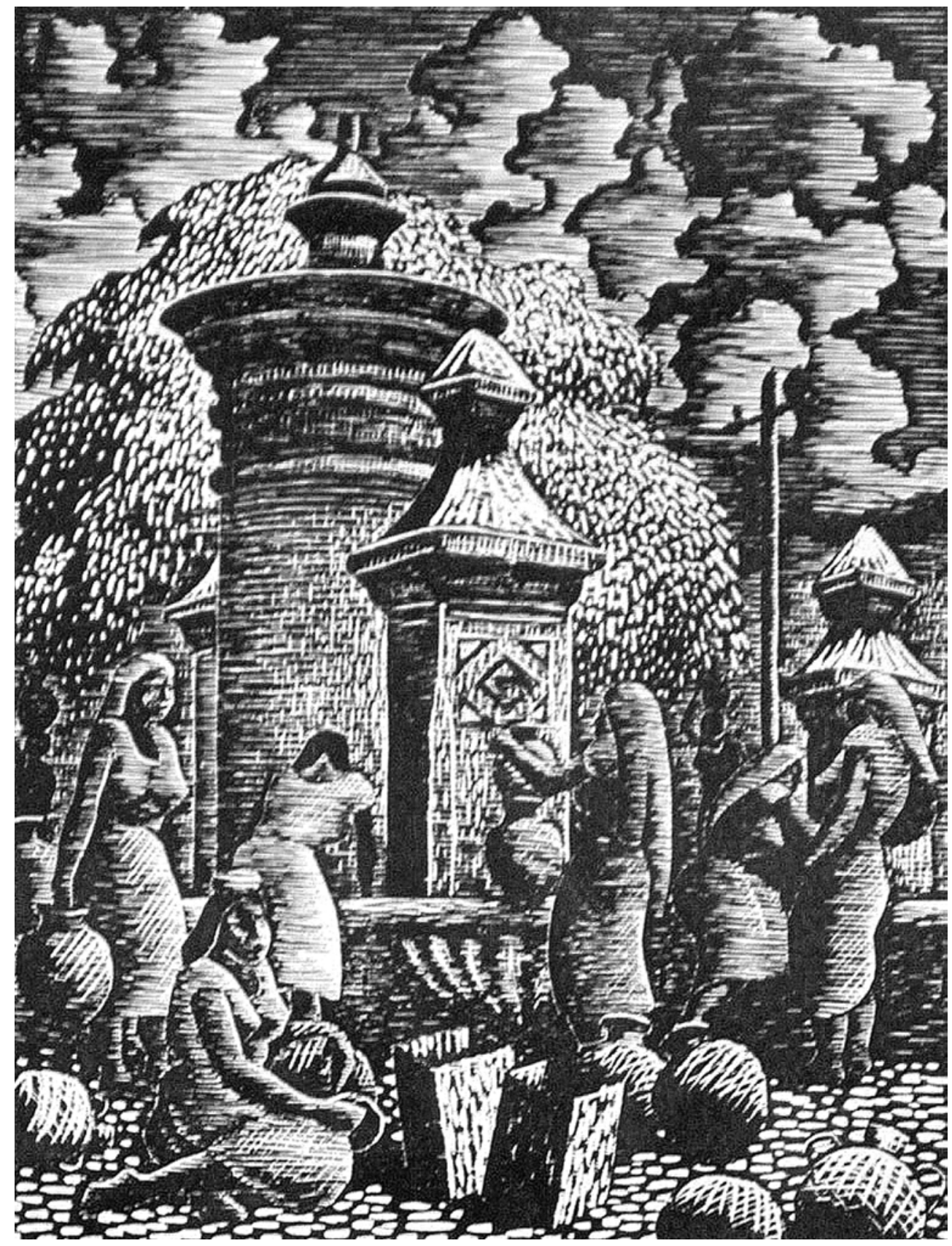

de los hechos de 1932, representa en su obra paisajes nacionales de carácter social y rural, exponiendo a campesinos e indígenas como retratos de su etnicidad y protagonistas de su historia. Muestra de ello es la obra "Primera reforma agraria de El Salvador" de 1935. 
Valero Lecha, aunque español de origen, fue cada vez más empapándose del entorno salvadoreño; en sus obras produce una pintura impregnada por el ambiente rural/indígena/campesino, desde mediados de la década de 1930 al decenio de 1950, con una clara idealización del mundo cotidiano de los habitantes de ese El Salvador indígena/campesino. Por su parte, José Mejía Vides, con la influencia de haber estudiado en México durante la década de 1920, se aboca a exaltar e idealizar la belleza étnica; visita las comunidades indígenas, en especial Panchimalco, de donde capta la naturaleza y la fisonomía del indígena en su medio habitual. También lo harían Julia Díaz y Noé Canjura, expresando en su arte esa ruralidad campesina/indígena, y que se volvería la realidad mestiza. Cuando estaba por finalizar la década de 1940, justamente en 1948, Toño Salazar, el caricaturista salvadoreño, elabora bocetos con imágenes humanas que representan a personajes indígenas que parece que danzan entre símbolos del mundo prehispánico, como extraídos de un códice indígena.

A partir de la segunda mitad del siglo XX, habrá muchos artistas plásticos que incluirán la estética indígena y los elementos prehispánicos en sus obras. Justamente, Antonio Bonilla, en 1954, en su obra denominada "La Conquista", expondría en una especie de tríptico renacentista una escena que hace referencia al encuentro sangriento de dos culturas: la europea y la mesoamericana, apareciendo las figuras de los conquistadores españoles como vencedores y los indígenas como vencidos, quizá emulando aquellas estampas de los códices indígenas elaboradas por los "indios amigos", acompañantes de los conquistadores. Por su parte, Camilo Minero mostraría en su obra a los más desposeídos, aquellos que la sociedad ha excluido y que muchas veces serían esos campesinos en los que claramente muestra su etnicidad, abordado dentro de la tendencia del realismo social (MARTE, 2009:22). Por otro lado, Carlos Cañas, durante sus primeros trabajos, produjo obras enmarcadas en la corriente indigenista. Además, en su obra abstracta se encuentran representaciones prehispánicas de la cultura maya. Benjamín Cañas elabora una obra sin título, en 1969, la cual muestra un personaje principal maya prehispánico, el que carga sobre sus hombros un enorme yugo; alrededor de él hay varios elementos prehispánicos mayas: rostros de mujeres y hombres de perfil maya; sus colores recuerdan los que se utilizan en la cerámica elaborada del mundo prehispánico. Raúl Elas Reyes, por su parte, abordó el abstraccionismo geométrico inspirándose en la escritura maya, explorando su carácter abstracto, en su obra "Jeroglíficos" de 1974 (Cea, 1986:159). 
Dentro del movimiento muralista, en las décadas de 1980 y 1990, Isaías Mata refleja en su obra la cultura indígena desposeída, pero en un papel más activo que en las anteriores representaciones, ya que le da a este grupo étnico un carácter de agentes de cambio como autores y actores de sus propias luchas históricas.

Con el boom de las investigaciones arqueológicas y antropológicas en el área maya, aparecen también en la plástica salvadoreña obras recargadas de elementos prehispánicos. Así, la obra "Popol Vuh" (1988), de Pedro Portillo se encuentra cargada de distintivos y símbolos de la cosmovisión mesoamericana, como la ceiba, el árbol sagrado de los mayas, el juego de pelota y sus jugadores, la deidad de Quetzalcoatl, las típicas casas mayas de las tierras bajas y otra gran cantidad de elementos alusivos a dicha cultura, como salidos de un vaso ceremonial policromo.

Al declararse, por la Unesco el sitio arqueológico Joya de Cerén como Patrimonio Cultural de la Humanidad, en 1993, se coloca de nuevo y con mucha fuerza, en el imaginario nacional el tema prehispánico en la identidad nacional. Así, artistas como Licry Bicard, explora las posibilidades estéticas del estilo que se muestra en la cerámica denominada “Copador", la que se hallaba presente en la aldea prehispánica de Joya de Cerén.

Al comienzo del silgo XXI, y con las nuevas tecnologías, las obras de carácter mixedmedia emergen más y más en el ámbito de las artes salvadoreñas. Así, tenemos la obra de Leyla Menbreño denominada "Mayatosh", término acuñado por la autora con la unión de maya y Macintosh, en la que se mezclan accesorios de ordenadores y gráficas bajorrelieves de la estética maya prehispánica; pero en la que también se podría percibir esa identidad global de las nuevas tecnologías y la identidad local, entendida, eso sí, desde un pasado prehispánico.

La estética prehispánica sigue jugando un papel importante en el imaginario nacional, legitimado y reproducido por el Estado salvadoreño. Muestra de ello es la imagen de la estructura principal del sitio arqueológico prehispánico Tazumal, la cual se puede apreciar en el fondo del anverso y reverso que decora el documento único de identidad, DUI, y que todos los ciudadanos salvadoreños mayores de 18 años, por ley, deben obtener. 
Como es de suponer, existen más ejemplos de proyectos y obras de artistas que a lo largo de los siglos XX y XXI, han plasmado en sus trabajos la estética indígena y/o prehispánica. Desde la identidad nacional salvadoreña, - como construcción a partir del Estado y sus instituciones reproductoras-, el nacional salvadoreño se desdibuja como un ser mestizo (parte europeo, parte indígena). Es desde ahí que, al pensarse, describirse, (re)inventarse y expresarse a través del patrimonio artístico, de alguna manera mostrará ese mito de origen, esa otra parte de su ser, el de ser salvadoreño.

\section{Referencias bibliográficas}

Alvarenga, Patricia. Los indígenas y el Estado: alianzas y estrategias políticas en la construcción del poder local en El Salvador. En: Darío E. Euraque, Jeffrey.

L. Gould, Charles L. Hale et al. Memorias del mestizaje. Cultura política en Centroamérica de 1920 al presente. Guatemala: Cirma, 2004.

Anderson, Benedict. Comunidades Imaginadas. Reflexiones sobre el origen y la difusión del nacionalismo. México: Fondo de Cultura Económica, 2007.

Bermejo Barrera, José Carlos. "La ideología del patrimonio y el nacimiento de la historia Basura”. Departamento de Historia, Universidad de Santiago, Galicia, España. 1986.

Cea, José Roberto. De la pintura en El Salvador. Editorial Universitaria. UES, San Salvador, 1986.

Ching, Erick. "Las masas, la matanza y el martinato en El Salvador: ensayos sobre 1932”. Erick Ching, Carlos Gregorio López Bernal y Virginia Tilley. San Salvador, El Salvador, UCA Editores, 2007.

D.O. N N$^{\mathrm{o}}$. 239, Tomo 15 de 16 de octubre de 1883. Sección Oficial, Ministerio de Gobernación y Fomento.

Escalante Arce, Pedro Antonio. Brasseur de Bourbourg. Esbozo biográfico. Talleres UCA, San Salvador, 1989.

Florescano, Enrique. "La creación del Museo Nacional de Antropología”. En: El Patrimonio Nacional de México II, Enrique Florescano, coordinador. Fondo de Cultura Económica, México, 1997.

Gould, Jeffrey L. Nacionalismo revolucionario y memoria local en El Salvador. En: Darío 
E. Euraque, Jeffrey L. Gould, Charles L. Hale et al. Memorias del mestizaje. Cultura política en Centroamérica de 1920 al presente. Guatemala: Cirma, 2004.

Gould, Jeffrey L. y Aldo Lauria-Santiago. "1932: rebelión en la oscuridad. Revolución, repression y memoria en El Salvador”. San Salvador, El Salvador. Ediciones Museo de la Palabra y la Imagen, 2008.

Hobsbawm, Eric and Terence Ranger, editores. "La invención de la tradición”. Editorial Crítica Barcelona, España, 2002.

Lara-Martínez, Rafael. "Balsamera bajo la guerra fría. El Salvador 1932, historia intelectual de un etnocidio”. San Salvador, El Salvador, Editorial Universidad Don Bosco, 2009.

-Política cultural y secuelas de 1932. Mujer e Indígena en el regionalismo salvadoreño. En: Revista Cultura, No. 90, mayo-agosto 2005. Concultura, San Salvador, El Salvador, 2005.

Lindo Fuentes, Héctor, Erick Ching y Rafael Lara-Martínez. Recordando 1932: La matanza, Roque Dalton y la política de la memoria histórica”. Traducción de Knut Walter. San Salvador, El Salvador, Facultad de Latinoamericana de Ciencias Sociales, Flacso, programa El Salvador, enero de 2010.

Lombardo de Ruiz, Sonia. "El patrimonio arquitectónico y urbano (de 1521 a 1900)”. En: El Patrimonio Nacional de México II, Enrique Florescano, coordinador. Fondo de Cultura Económica, México, 1997.

López Bernal, Carlos Gregorio. "Tradiciones inventadas y discursos nacionalistas: el imaginario nacional de la época liberal en El Salvador, 1876-1932”. Editorial e Imprenta Universitaria, 2007. San Salvador, El Salvador.

"El pensamiento de los intelectuales liberales salvadoreños sobre el indígena, a finales del siglo XIX”, Boletín AFEHC N41, publicado el 04 junio 2009, disponible en: http://afehchistoriacentroamericana.org/index.php?action=fi_aff\&id=2198.

"MARTE, Revisiones: encuentro con el arte salvadoreño". Museo de Arte de El Salvador, San Salvador, 2007.

Artista del mes: mayo 2003-2009. Museo de Arte de El Salvador, San Salvador, 2009.

Manrrique, Jorge Alberto. Las artes plásticas. En: El Patrimonio Nacional de México II, 
Enrique Florescano, coordinador. Fondo de Cultura Económica, México, 1997.

Marroquín, Alejandro D. El problema indígena en El Salvador. En: Instituto Indigenista Americano. Revista América Indígena, Volumen XXXV, No. 4, octubre-diciembre, 1975. México.

Smith, Anthony. "El fundamento étnico de la identidad nacional”. En: Smith, Anthony D. La identidad nacional, Capítulo 2, Trama Editorial, Madrid, 1997, pp-17-39. http://www. cholonautas.edu.pe/modulo/upload/A\%20Smith1.pdf.

Soto Quirós, Ronald y Díaz Arias, David. "Mestizaje, indígenas e identidad nacional en Centroamérica: de la colonia a las repúblicas Liberales”. En Cuaderno de Ciencias Sociales 143. Flacso, Costa Rica, 2007.

Wade, Peter. Raza y etnicidad en Latinoamérica. Ediciones ABYA-YALA, Quito, Ecuador, 2000. 


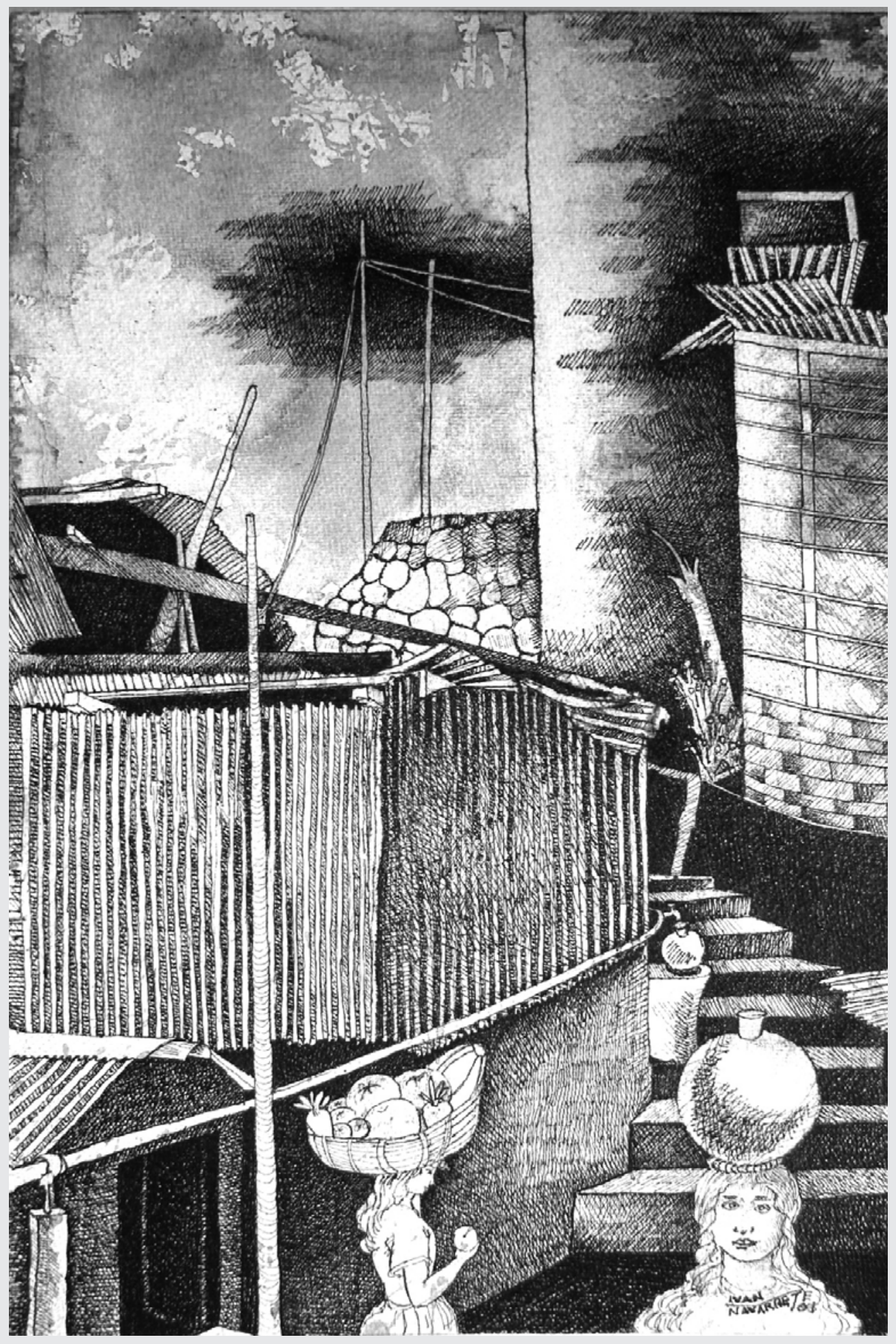

